\title{
The interplay between human population dynamics and flooding in Bangladesh: a spatial analysis
}

\author{
GIULIANO DI BALDASSARRE ${ }^{1}$, KUN YAN ${ }^{2}$, MD RUKNUL FERDOUS ${ }^{2} \&$ \\ LUIGIA BRANDIMARTE ${ }^{2}$ \\ 1 Department of Earth Sciences, Uppsala University, Uppsala, Sweden \\ giuliano.dibaldassarre $@$ geo.uu.se \\ 2 UNESCO-IHE Institute for Water Education, Delft, The Netherlands
}

\begin{abstract}
In Bangladesh, socio-economic and hydrological processes are both extremely dynamic and interrelated. Human population patterns are often explained as a response, or adaptation strategy, to physical events, e.g. flooding, salt-water intrusion, and erosion. Meanwhile, these physical processes are exacerbated, or mitigated, by diverse human interventions, e.g. river diversion, levees and polders. In this context, this paper describes an attempt to explore the complex interplay between floods and societies in Bangladeshi floodplains. In particular, we performed a spatially-distributed analysis of the interactions between the dynamics of human settlements and flood inundation patterns. To this end, we used flooding simulation results from inundation modelling, LISFLOOD-FP, as well as global datasets of population distribution data, such as the Gridded Population of the World (20 years, from 1990 to 2010) and HYDE datasets (310 years, from 1700 to 2010). The outcomes of this work highlight the behaviour of Bangladeshi floodplains as complex humanwater systems and indicate the need to go beyond the traditional narratives based on one-way cause-effects, e.g. climate change leading to migrations.
\end{abstract}

Key words Bangladesh; socio-hydrology; river flooding; human population dynamics

\section{INTRODUCTION}

Much progress has been made in the field of flood risk over the past decades (e.g. Apel et al. 2009, Pappenberger et al. 2012, Winsemius et al. 2013). However, there is still a lack of understanding of the complex interplay between the physical and social components of risk (e.g. hazard, exposure, vulnerability or resilience). To this end, there is a need for inter- or trans-disciplinary research to explore the socio-hydrology (Sivapalan et al. 2012) of floodplains and deltas with a focus on the interactions and feedbacks between social and hydrological processes (Di Baldassarre et al. 2013a,b).

Bangladesh is the lowest riparian of three great river basins: the Ganges, Brahmaputra and Meghna (GBM) basins extending over Bhutan, China, India and Nepal. Bangladesh has a large, growing population with more than $32 \%$ living below the lower poverty line (Terwisscha van Scheltinga et al. 2013), very high population density and fierce competition for increasingly degraded natural resources.

In Bangladesh, the interplay between social and hydrological processes is very dynamic. People move between rural and urban areas in search of better livelihood opportunities, or as a response to flood events or geomorphologic impacts, e.g. riverbank erosion. At the same time, waterways change courses scouring away riverbanks (Sarker et al.2003) and arable land on chars (shoals) and coastal sites, while the flow into new urban spaces in response to rising water tables (water logging) and the interconnected floodplain development in Dhaka generate dynamic flood risk conditions. Bangladeshi cities are growing rapidly with expanding economies, along with enhanced levels of social inequality (Banks et al. 2011). This makes it one of the most interesting case studies for the new Scientific Decade of the International Association of Hydrological Sciences (IAHS), Panta Rhei, focusing on changes in hydrology and society (Montanari et al. 2013).

One of the current coping strategies of people affected by hydrological processes is migration, but little is currently understood in terms of who moves (women versus men, educated and skilled individuals versus the poorest), why they move (as opposed to other flood or erosion affected households in disaster zones), where they move (secondary urban centres or primary cities), how they move (circular or temporary migration; rural to urban), what risks or opportunities they face in urban destinations (including flood or disaster risk; coping strategies; negotiation with local authorities), and how this migration process affects flood risk and sustainable development in the host locations. 
These knowledge gaps are compounded by current approaches of development interventions and policy prescriptions dealing with flood disaster response, flood management, urban flood resilience and urban development, which tend to still be sectoral and top-down oriented.

In this context, this paper describes an initial attempt to explore the interplay between floods and societies in Bangladeshi floodplains. In particular, we performed a spatially-distributed analysis of the flood inundation patterns and dynamics of human settlements over recent decades.

\section{METHOD}

Figure 1 shows a map of Bangladesh highlighting the areas that are prone to river flooding. This map was made using a simple 2-D model code, LISFLOOD-FP (Bates et al. 2010), to simulate highmagnitude flood conditions of the GBM system. The spatial distribution of inundation patterns were found to match with the floodplain maps reported in the scientific literature (Pappenberger et al. 2012, Winsemius et al. 2013) at accuracy adequate for the scope of this study.

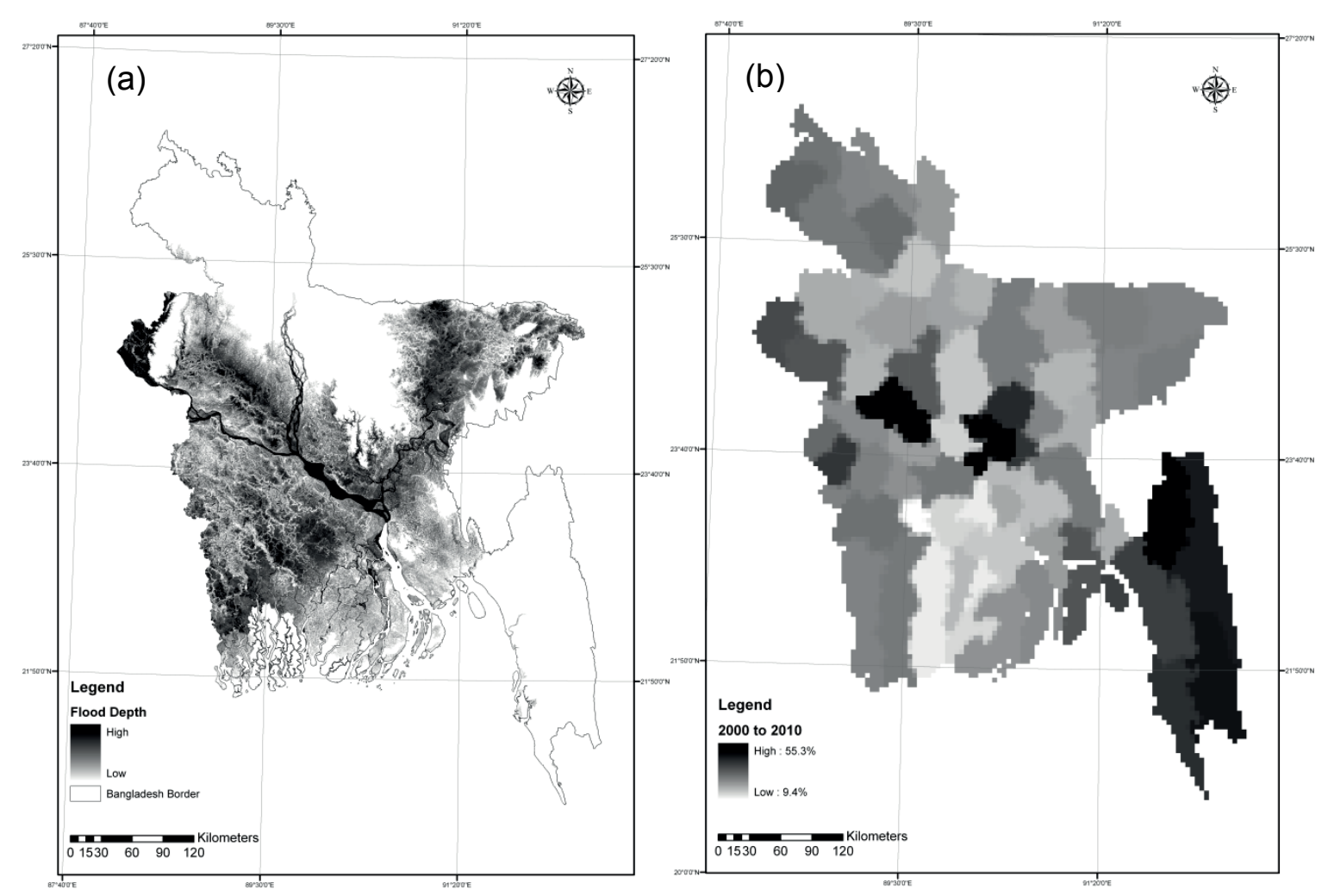

Fig. 1 Flood inundation modelling results in terms of maximum water depth used to delineate floodplain areas in Bangladesh (a). Ratio of 10-year population increase in Bangladesh, from 2000 to 2010 (b).

The dynamics of human population patterns were examined by using global datasets of population distribution data. The first dataset was the gridded population of the world (GPW), which has a resolution of around $5 \mathrm{~km}$ and relies on national statistical office estimates of population, such as census data. As an example of spatial analysis of human population dynamics, Fig. 1 shows the percentage of population growth between 2000 and 2010. Similar patterns were found between 1990 and 2000 in Bangladesh. The inundation map of Fig. 1 was then used to assess the evolution of the proportion of the population living in flood prone areas. It was found that the ratio of people living in the Bangladeshi floodplains has been constant at around $67 \%$ and has not significantly changed over the past 25 years.

To explore longer-term dynamics, we utilised the HYDE dataset (Klein Goldewijk et al. 2010) between 1700 and 2010. Figure 2(a-(c) shows the growth of the total human population in the whole of Bangladesh, the population in flood prone areas, and the ratio of people living in floodplains. 
While Fig. 2(d)-(f) shows the total urban area, the urban area within the floodplain region, and the ratio of urban territory in flood prone areas. It is interesting to note that, despite the growing population and urban areas, their ratios in floodplains (Fig. 2(c) and (f)) have not changed significantly over the past 300 years.
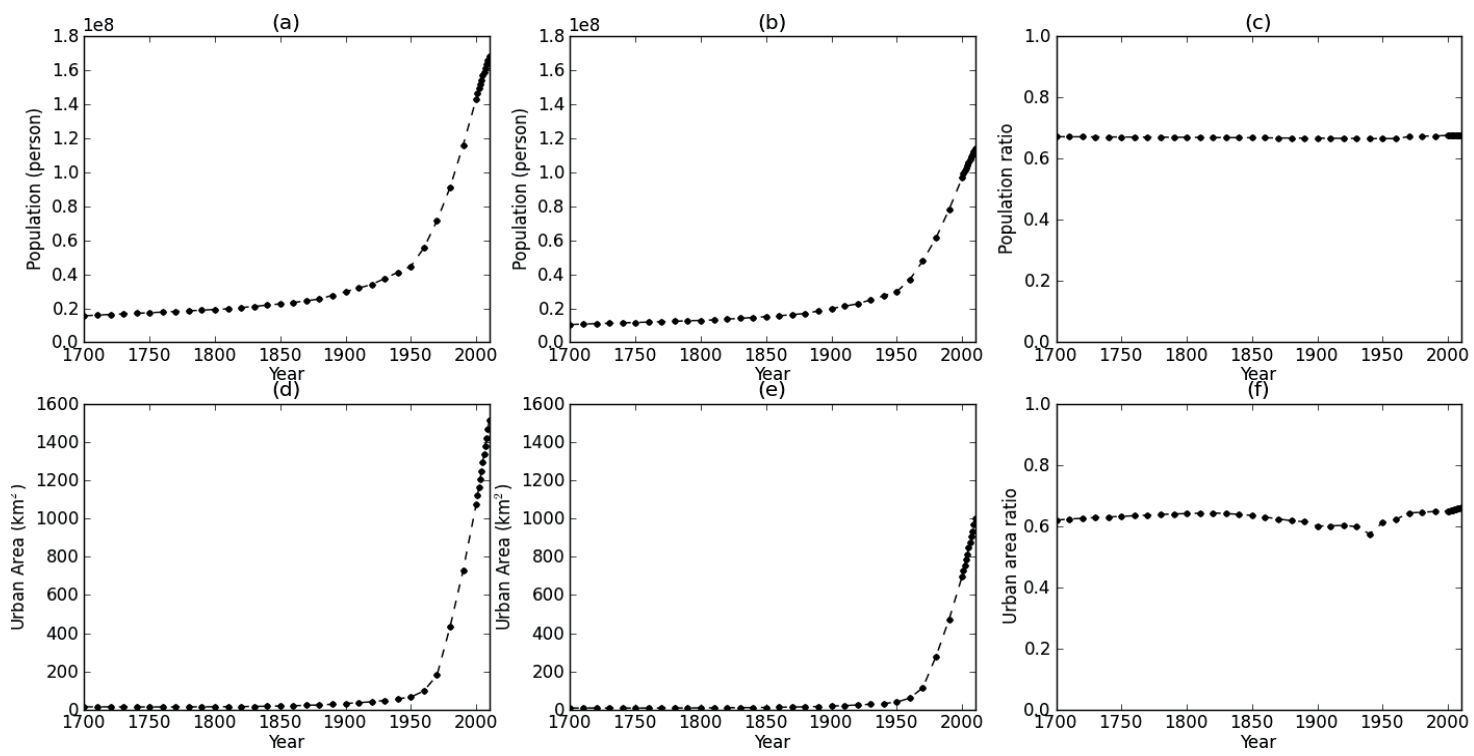

Fig. 2 Population and urban areas in Bangladesh from 1700 to 2010: (a) total population, (b) population in floodplain, (c) ratio of population (floodplain versus nation), (d) total urban area, (e) urban area in floodplain, and (f) ratio of urban area (floodplain versus nation).

\section{DISCUSSION AND CONCLUSIONS}

This study shows that, while the number of people living in Bangladeshi has grown remarkably over the past decades (Fig. 2), the proportion of people living in floodplain areas has not significantly changed. A similar behaviour has been observed for urban areas (Fig. 2(d)-(f)). Interestingly, this result is rather different to what has been observed in many European or North American systems. In the Netherlands, for instance, the numbers of people living in floodplain areas as well as urban areas have significantly increased over the past decades (de Moel et al. 2011). Indeed, many European and North American systems have experienced a continuous construction and reinforcement of flood defence/control structures to reduce the frequency of flooding events and therefore facilitate/trigger urban development in floodplains. This led to the typical shift from frequent floods to rare, but potentially catastrophic, flood disasters, which is often observed in societies that tend to "fight floods" (Di Baldassarre et al. 2013a,b). In contrast, the ratio of people living in flood prone areas in Bangladesh has been almost constant over the last 300 years (Fig. 2). Hence, the present work suggests the hypothesis that Bangladesh is a human-water system where a stable inter-relationship between people and floods has been established (e.g. "living with floods", Di Baldassarre et al. 2013a,b). This is an intriguing hypothesis that should be carefully tested with a more comprehensive and detailed analysis of the interplay between social and hydrological processes in Bangladesh.

Figure 1 showed that the growth of human population has been relatively small in the southwest coastal region of Bangladesh. This can be explained by the emigration process from this region as a response to bio-physical changes, such as saline intrusion and flooding (e.g. cyclone Alia) as suggested by a number of social studies (e.g. Reuveny 2007). However, we believe that we need to go beyond these traditional narratives based on one-way cause-effect (Fig. 3).

In fact, hydrological studies of the southwest coastal region of Bangladesh (e.g. Mondal et al. 2013) have demonstrated that the changes in water salinity, tidal water level and flooding in this region were (in turn) mainly due to human interventions, such as upstream diversion and coastal polders. Hence, humans have been shaping the bio-physical system (e.g. development), which in 
turn has shaped patterns of human settlement (e.g. migration). This region has therefore experienced a complex web of interactions between social and physical processes (Fig. 3) that can only be explained by examining it as a coupled human-water system, while recognizing the heterogeneity and spatial distribution of this interplay.

Lastly, it should be mentioned that, despite its relatively high resolution, the GPW dataset is based on large districts of Bangladesh (Fig. 1). This is one of the main limitations of this spatial analysis and we are currently collecting census data and conducting survey interviews at sub-district levels to validate our results and gain a better understanding of the dynamics of human population patterns and their link with bio-physical processes.
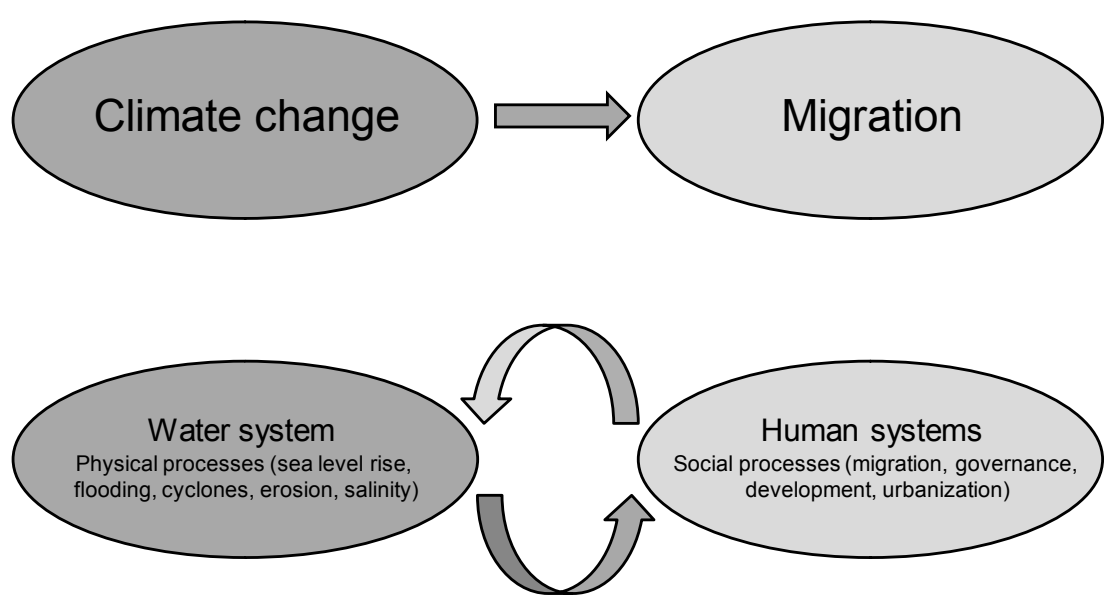

Fig. 3 Example of current narratives [top] and proposed research framework [bottom].

\section{REFERENCES}

Apel, H., et al. (2009) Flood risk analyses - how detailed do we need to be? Natural Hazards, 49, 79-98.

Banks, N., Roy, M., and Hulme, D. (2011) Neglecting the urban poor in Bangladesh: research, policy and action in the context of climate change. Environment and Urbanization 23(3), 487-502.

Bates, P. D., Horritt, M. S. and Fewtrell, T.J. (2010) Simple inertial formulation of the shallow water equations for efficient twodimensional flood inundation modelling. Journal of Hydrology 387, 33-45.

de Moel, H., Aerts, J. C. J. H., and Koomen, E. (2011) Development of flood exposure in the Netherlands during the 20th and 21 st century. Global Environmental Change, 620-627.

Di Baldassarre, G., et al. (2013a) Towards understanding the dynamic behaviour of floodplains as human-water systems, Hydrology and Earth System Sciences 17, 3235-3244.

Di Baldassarre, G., et al. (2013b) Socio-hydrology: conceptualising human-flood interactions, Hydrology and Earth System Sciences, 17, 3295-3303.

Klein Goldewijk, K., et al. (2010) The HYDE 3.1 spatially explicit database of human-inudced global land-use change over the past 12000 years. Global Ecology and Biogeography 20(1), 73-86.

Mondal, M. S., et al. (2013) Hydro-Meteorological Trends in Southwest Coastal Bangladesh: Perspectives of Climate Change and Human Interventions. American Journal of Climate Change, 2, 62-70.

Montanari, A., et al. (2013) Panta Rhei - Everything Flows: Change in hydrology and society - The IAHS Scientific Decade, 2013-2022, Hydrol. Sci. J., 58, 1256-1275.

Pappenberger, F., et al. (2012) Deriving global flood hazard maps of fluvial floods through a physical model cascade, Hydrology and Earth System Sciences, 16, 4143-4156.

Reuveny, R. (2007) Climate change-induced migration and violent conflict. Political Geography, 26(6), 656-673.

Sarker M. H., et al. (2003) Rivers, chars and char dwellers of Bangladesh. Intl. J. River Basin Management, 1(1), 61-80.

Sivapalan, M., Savenije, H. G. and Blöschl, G. (2012) Socio-hydrology: A new science of people and water. Hydrological Processes, 26(8), 1270-1276.

Sultana, P., Thompson, P. and C. Green (2008) Can England learn lessons from Bangladesh in introducing participatory floodplain management? Water Resources Management 22(3), 357-376.

Terwisscha van Scheltinga, C., et al. (2013) Capacity development in scenario development in integrated water resources management in Bangladesh. Proceedings of the International Conference on Climate Change Impact and Adaptation, I3CIA-2013, Gazipur, Bangladesh.

Winsemius, H. C., et al. (2013) A framework for global river flood risk assessments. Hydrol. Earth System Sci. 17, 1871-1892. 